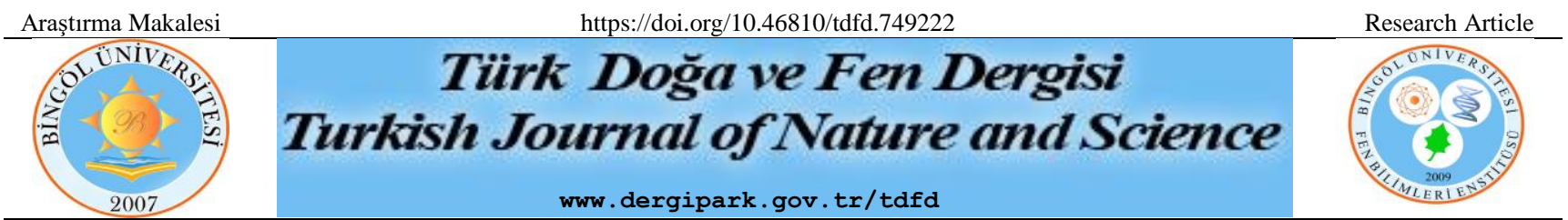

\title{
Bazı Çemen (Trigonella foenum-graecum L.) Genotiplerinin Vejetatif Aksam ve Tohumlarının Yağ Asit Komposizyonunun Belirlenmesi
}

\author{
Fatma AKBAY ${ }^{1 *}$, Adem EROL ${ }^{1}$ \\ ${ }^{1}$ Kahramanmaraş Sütçü İmam Üniversitesi, Ziraat Fakültesi, Tarla Bitkileri Bölümü, Bingöl, Türkiye \\ Fatma AKBAY ORCID No: 0000-0002-0156-9974 \\ Adem EROL ORCID No: 0000-0002-3381-8402 \\ *Sorumlu yazar: ftm.akbay01@gmail.com
}

(Alınış: 08.06.2020, Kabul: 04.10.2021, Online Yayınlanma: 31.12.2021)

\begin{abstract}
Anahtar Kelimeler Çemen, Yağ asit bileşenleri, Trigonella foenum graecum $\mathrm{L}$.

Öz: $\mathrm{Bu}$ araştırma; 18 farklı çemen genotipinin vejetatif aksam ve tohumlarının yağ asit kompozisyonunu belirlemek üzere Kahramanmaraş ekolojik koşullarında 2016-2017 yılı içerisinde yürütülmüsstür. Deneme tesadüf bloklar deneme desenine göre üç tekerrürlü olarak kurulmuştur. Çalışma sonuçlarına göre çemen bitkisinin vejetatif aksamının yağ asit bileşenleri; araşidik asit $\% 37,34-50,92$, linoleik asit \%14,15-29,83, palmitik asit \%10,01-12,37, bütirik asit \%3,42-9,28, elaidik asit \%2,15-11,14, stearik asit \%2,33-3,03 ve oleik asit \%0,20-0,51 arasında değiştiği belirlenmiştir. Çemen tohumlarının yağ asit bileşenleri ise; linolenik asit \%36,92-43,82, gama linoleik asit \%23,39-29,74, oleik asit \%12,79-19,27, palmitik asit \%9,77-13,68 ve stearik asit \%3,54,8 arasında değiştiği saptanmıştır. Çalışmada çemen tohumların yağ oranı \%3,01-5,34 arasında değiştiği tespit edilmiştir.
\end{abstract}

\section{Determination of Fatty Acid Composition of Some Fenugreek (Trigonella foenum-graecum L.) Genotypes Vegetative Parts and Seeds}

Keywords Fenugreek, Oil acid components, Trigonella foenumgraecum $\mathrm{L}$.

\begin{abstract}
This research was carried out in 2016-2017 under the ecological conditions of Kahramanmaras to determine the fatty acid composition of above ground parts and seeds of 18 different fenugreek genotypes. The experiment was set up in a Randomized Complete Block Design with three replications. According to the results of the study, the fatty acid components of the vegetative component of the fenugreek plant; arachidic acid 37.34-50.92\%, linoleic acid 14.15$29.83 \%$, palmitic acid $10.01-12.37 \%$, butyric acid $3.42-9.28 \%$, elaidic acid $2.15-11.14 \%$, stearic acid $2.33-3.03 \%$ and oleic acid $0.20-0.51 \%$ it has been determined that it has changed. When the fatty acid components of fenugreek seeds are examined; It was found that linoleic acid ranged between $36.92-43.82 \%$, linolenic acid $23.39-29.74 \%$, oleic acid $12.79-19.27 \%$, palmitic acid 9.77$13.68 \%$ and stearic acid $3.5-4.8 \%$. In addition, it has been determined that the oil content of seeds varies between $3.08-5.34 \%$.
\end{abstract}

\section{GİRIŞ}

Çemen; Trigonella foenum-graecum L., tek y1llık ve dünyanın birçok yerinde baharat amaçlı yetiştirilen bir baklagil bitkisidir. Bat1-Güney Asya, Avrupa, KuzeyGüney Amerika, Kuzey Afrika ve Avustralya kıtalarında yetiştiği bilinmektedir [1]. Çemen bitkisi tıp, geleneksel tıp, eczacılık ve kozmetik gibi alanlarda yaygın olarak kullanılmaktadır. Gıda endüstrisinde lezzet arttırıcı, bakteriyel hastalıkları önleme ve raf ömrünü uzatmak için kullanıldığı bilinmektedir [2]. Tıpta ise infüzyonlar, su ve alkol özleri, tentürler, antidepresan ilaçları ve kas büyüme takviyeleri hazırlamak için kullanılmaktır [3]. Yaprakları sebze olarak tüketilip salata yapımında, yeşil otu ise hayvan beslenmesinde iyi bir protein kaynağıdır. Ayrıca sığırlarda şişmeye neden olmaması ve diosgenin gibi hayvan büyümesini teşvik eden maddeler içermesi nedeniyle yüksek kaliteli bir yem olarak tanımlanmaktadır $[4,5]$.

Tohumları fosfor, kükürt, magnezyum ve kalsiyum gibi elementler bakımından zengindir ancak çinko, manganez ve bakır daha az miktarda ihtiva etmektedir [3]. Çemen tohumları flavonoidler, kolin, karoten, trigonellin ve diğer fonksiyonel elementler içeren uçucu yağları içermektedir [6]. Tohumları doymamış 
yağ asitleri açısından da zengindir [7]. Doymuş ve doymamış yağ asitleri insan ve hayvan beslenmesinde önemli bir rol oynamaktadır. Özellikle F vitamini olarak adlandırılan linoleik, linolenik ve araşhidik asit esansiyel yağ asitleri olarak bilinmektedir. $\mathrm{Bu}$ organizmalar hayvanlar tarafindan sentez edilemedikleri için gıdalar vasıtasıyla alınmaktadır. Linoleik asit (omega 6) ve oleik asit (omega 9) beyin büyümesi, bağışıklık sistemini güçlendirmesi ve kalp hastalığını önlemesi gibi hayati fonksiyonları etkilediği bilinmektedir [8]. Palmitik ve stearik asit bitkideki en önemli doymuş yağ asidi olarak tanımlanmaktadır [9]. Araşhidik asit ise kanser tedavisinde kullanılarak tümör hücrelerinin azaltılmasını sağlamaktadır [10].

$\mathrm{Bu}$ çalışma; Kahramanmaraş ekolojik koşullarında farklı çemen genotiplerinin vejetatif aksamı ve tohumlarının yă̆ asit bileşenlerini belirlemek için gerçekleştirilmiştir.

\section{MATERYAL VE METOT}

$\mathrm{Bu}$ araştırma, Kahramanmaraş Sütçü İmam Üniversitesi Ziraat Fakültesi, Tarla Bitkileri Bölümüne ait araştırma ve uygulama alanında 2016-2017 yetiştirme sezonunda yürütülmüştür. Kahramanmaraş ili Türkiye'nin $37^{\circ} 36^{\prime}$ Kuzey enlemleri ve $46^{\circ} 56^{\prime}$ Doğu boylam dereceleri arasında yer almakta ve bölgede yazları sıcak ve kurak, kışları 1lık ve yağışı hava hâkim olmaktadır. Tablo 1'deki iklim verileri incelendiğinde ekimin yapıldığı dönemde toplam yağış $522,6 \mathrm{~mm}$ olarak gerçekleşmiş ve en yüksek yağış Ocak ayında, en düşük yağış ise Haziran ayında gerçekleşmiştir. En yüksek sıcaklık $26,4{ }^{\circ} \mathrm{C}$ ile Haziran ayında, en düşük sıcaklık $3,8{ }^{\circ} \mathrm{C}$ ile Ocak ayında gerçekleşmiştir. Ekimin yapıldığı dönemde ortalama nispi nem \%53,7 olarak gerçekleşmiştir.

Tablo 1. Kahramanmaraş İlinin 2016-2017 İklim Verileri (Kahramanmaraş Meteoroloji Müdürlüğü)

\begin{tabular}{lccc}
\hline & $\begin{array}{c}\text { Ortalama } \\
\text { sıcaklık }\left({ }^{\circ} \mathbf{C}\right)\end{array}$ & $\begin{array}{c}\text { Toplam } \\
\text { yağış }(\mathbf{m m})\end{array}$ & $\begin{array}{c}\text { Ortalama Nispi } \\
\text { Nem }(\%)\end{array}$ \\
\hline Kasım & 11,1 & 36,8 & 49,5 \\
Aralık & 4,5 & 105,0 & 67,9 \\
Ocak & 3,8 & 126,7 & 65,9 \\
Şubat & 7,4 & 3,7 & 44,0 \\
Mart & 12,2 & 74,5 & 55,4 \\
Nisan & 15,8 & 67,8 & 49,0 \\
Mayıs & 19,6 & 105,0 & 55,0 \\
Haziran & 26,4 & 3,1 & 42,9 \\
\hline Ort./Top. & 12,6 & 522,6 & 53,7 \\
\hline
\end{tabular}

Araştırmanın kurulduğu 0-30 cm'lik kısmından alınan toprak örneğine göre deneme alanı killi bir yapıya sahiptir. Topraktaki potasyum $\left(\mathrm{K}_{2} \mathrm{O}\right) 53 \mathrm{~kg} \mathrm{da}^{-1}$, yarayışlı fosfor $\left(\mathrm{P}_{2} \mathrm{O}_{5}\right) 6,29 \mathrm{~kg} \mathrm{da}^{-1}$, topraktaki organik madde miktarı \%1,66, kireç miktarı \%3,91 (CaCO3) ve pH değeri 7,66 olarak belirlenmiştir. Analiz sonucuna göre topraktaki bitki için yarayışlı potasyum yüksek seviyede ve yarayışlı fosforun orta seviyede olduğu saptanmıştır.

Çalışma tesadüf bloklar deneme desenine göre üç tekerrürlü olarak yürütülmüştür. Araştırmada kullanılan çemen genotiplerinin 5'i yurt dışından
(Afganistan 1, Afganistan 2, Irak 1, Irak 2, Irak 3) ve 13 genotip yurt içinden (Adana 1, Adana 2, Adana 3, Mardin 1, Urfa 1, Urfa 2, Urfa 3, Urfa 4, Antep 1, Antep 2, Kayseri 1, Maraş 1, Maraş 2) temin edilmiştir. Denemede her parsel $5 \mathrm{~m}$ uzunluğunda $20 \mathrm{~cm}$ sira aralıklı 6 ekim sırasından oluşmuştur. Genotiplerin bin tane ağırlıklarına göre yaklaşık $4 \mathrm{~kg} \mathrm{da}^{-1}$ tohum düşecek şekilde her sıraya elle ekim yapılmıştır ve ekim ile birlikte $3 \mathrm{~kg} \mathrm{da}^{-1} \mathrm{~N}$ ve $8 \mathrm{~kg} \mathrm{da}^{-1} \mathrm{P}_{2} \mathrm{O}_{5}$ gübreleri uygulanmıştır.

Denemede, her parselin yanlardan birer sıra kenar tesir bırakıldıktan sonra 4 sıranın başından ve sonundan 25 cm'lik kısım atılmıştır. Parseldeki $0,4 \mathrm{~m}^{2}$ 'lik alandan vejetatif aksam için örnekler alınmıştır. Geri kalan kısım ise tohum hasadı için ayrılmıştır. Vejetatif aksam $70{ }^{\circ} \mathrm{C}$ ayarlanmış etüvde 48 saat kurutulmuştur. Tohum ve vejetatif aksam örnekleri $1 \mathrm{~mm}$ elekli değirmen makinasında ögütüldükten sonra paketlenip analizler için hazır hale getirilmiştir.

Ham yă̆ analizi AOAC [11]'de belirtilen yönteme göre yapılmıştır. Yağ asit bileşenleri tespitinde; 0,1 g yağ alınarak $15 \mathrm{ml}$ ağzı kapaklı tüpe konulmuştur. Üzerine $1 \mathrm{ml} 2 \mathrm{~N}$ metanollü KOH çözeltisi ilave edilip, $2 \mathrm{dk}$ vortekslenmiştir. $\mathrm{Bu}$ işlemi takiben $15 \mathrm{dk}$ bekletilip, üzerine $10 \mathrm{ml}$ hegzan ilave edilerek iyice karıştırılmıştır. Sonra faz ayrımı olması için 7000 rpm de $10 \mathrm{dk}$ santrifüj edilmiştir. Üst fazdan 1 mikrolitre GC cihazına enjeksiyon yapılmıştır. Metilleştirildikten sonra Alev İyonlaştırıcı Dedektörlü (FID), Shimadzu Gaz Kromatografi (Model 2025) ile analiz edilmiştir. Analiz işlemlerinde Supelco 37 Component Mix sertifikalı STD, Teknocroma marka TR-CN100 kolon kullanılmıştır. Kolonun firını için $80^{\circ} \mathrm{C}^{\prime}$ den başlanarak 2 dakika bekletilmiştir. Daha sonra, dakikada $5 \quad{ }^{\circ} \mathrm{C}$ artış sağlanıp $140^{\circ} \mathrm{C}$ sıcaklığa ulaştırılmıştır ve bu sıcaklıkta 2 dakika tutulmuştur. Bu işlemden sonra dakikada $3{ }^{\circ} \mathrm{C}$ 'lik bir artışla $240{ }^{\circ} \mathrm{C}$ 'de 5 dakika daha bekletilmiştir. Toplam analiz süresi 61 dakikadan oluşmuştur. Helyum taşıyıcı gaz olarak kullanılmış ve akış hızı $30 \quad \mathrm{ml} \quad \mathrm{dk}^{-1}$,ya ayarlanmıştır. Kullanılan gaz akışları $\mathrm{H} 2=40 \mathrm{ml} \mathrm{dk}^{-1}$ ve kuru hava $=400 \mathrm{ml} \mathrm{dk}^{-1}$ olarak belirlenmiştir.

\section{1. İstatistik Analizleri}

Araştırma sonucunda elde edilen sonuçlarının varyans analizi SAS istatistiki paket programında yapılmış, ortalamaların karşılaştırılmasında ise Duncan çoklu karşılaştırma testi kullanılmıştır [12].

\section{BULGULAR}

Yapılan analiz sonuçlarına göre çemen bitkisinin vejetatif aksamında toplam 31 adet yağ asit bileşenleri belirlenmiştir. Fakat bu 31 asidin \%95'i miktar bakımından 7 yağ asidinde toplanmıştır. Bu nedenle çemen bitkisinin vejetatif aksamında incelemelerimiz 7 yağ asidi üzerinde gerçekleşmiştir. Araştırmada incelenen yağ asitleri istatistiki açıdan önemli olduğu $(\mathrm{P} \leq 0,01)$ Tablo 2'de görülmektedir. Yine aynı çizelgede ortalamalar içerisinde en fazla oranda 
belirlenen yă̆ asidi bileşeni araşidik asit olup (\% 45,52 ), en yüksek değer \% 50,92 oranı ile Maraş-2 genotipinde elde edildiği görülmektedir. $\mathrm{Bu}$ oranı linoleik asit $(\% 17,59)$, palmitik asit $(\% 11,46)$, bütirik asit $(\% 5,52)$, elaidik asit $(\% 5,05)$, stearik asit $(\% 2,61)$ ve oleik asit $(\% 0,30)$ izlemiștir. Tablo 2 incelendiğinde araşidik asit \%37,34-50,92, linoleik asit $\% 14,15-29,83$, palmitik asit \%10,01-12,37, bütirik asit
$\% 3,42-9,28$, elaidik asit \%2,15-11,14, stearik asit $\% 2,33-3,03$ ve oleik asit \%0,20-0,51 arasında değiștiği gözlenmiştir. En yüksek değerler linoleik asit Adana-2, palmitik asit Kayseri-1, bütirik asit Adana-1 genotipinde saptanmıştır. Ayrıca elaidik asit, stearik asit ve oleik asit oranları en yüksek Adana-3 genotipinde tespit edilmiştir (Tablo 2).

Tablo 2. Çalışmada kullanılan çemen genotiplerinin vejetatif aksamına ait yağ asit bileşenleri

\begin{tabular}{|c|c|c|c|c|c|c|c|}
\hline Genotipler & $\begin{array}{c}\text { Bütirik } \\
\text { Asit }(\%)\end{array}$ & $\begin{array}{l}\text { Palmitik } \\
\text { Asit (\%) }\end{array}$ & $\begin{array}{c}\text { Stearik } \\
\text { Asit (\%) }\end{array}$ & $\begin{array}{c}\text { Elaidik } \\
\text { Asit }(\%)\end{array}$ & $\begin{array}{c}\text { Oleik } \\
\text { Asit }(\%)\end{array}$ & $\begin{array}{l}\text { Linoleik } \\
\text { Asit (\%) }\end{array}$ & $\begin{array}{l}\text { Araşidik } \\
\text { Asit (\%) }\end{array}$ \\
\hline & $* *$ & $* *$ & $* *$ & $* *$ & $* *$ & $* *$ & $* *$ \\
\hline Adana-1 & $9,28^{\mathrm{a}}$ & $11,69^{\text {bcd }}$ & $2,40^{\mathrm{ef}}$ & $2,88^{\mathrm{k}}$ & $0,22^{\text {fgh }}$ & $14,21^{\mathrm{lm}}$ & $49,11^{\mathrm{ab}}$ \\
\hline Adana-2 & $5,17^{\mathrm{f}}$ & $10,03^{\mathrm{f}}$ & $2,74^{\mathrm{bc}}$ & $6,15^{\mathrm{f}}$ & $0,43^{b}$ & $29,83^{\mathrm{a}}$ & $37,34^{\text {de }}$ \\
\hline Adana-3 & $3,70^{\mathrm{kl}}$ & $10,96^{\mathrm{f}}$ & $3,03^{\mathrm{a}}$ & $11,14^{\mathrm{a}}$ & $0,51^{\mathrm{a}}$ & $19,45^{\mathrm{e}}$ & $38,54^{\mathrm{ced}}$ \\
\hline Afganistan-1 & $6,11^{\mathrm{e}}$ & $11,52^{\text {cde }}$ & $2,54^{\text {cdef }}$ & $2,27^{\mathrm{mn}}$ & $0,22^{\text {fgh }}$ & $14,39^{1}$ & $50,14^{\mathrm{ab}}$ \\
\hline Afganistan-2 & $8,66^{b}$ & $11,31^{\mathrm{de}}$ & $2,58^{\text {cdef }}$ & $2,33^{\mathrm{mn}}$ & $0,20^{\mathrm{h}}$ & $14,36^{1}$ & $49,95^{\mathrm{ab}}$ \\
\hline Antep-1 & $3,92^{\mathrm{kj}}$ & $11,40^{\text {cde }}$ & $2,37^{\text {ef }}$ & $7,67^{\mathrm{d}}$ & $0,31^{\text {cde }}$ & $20,36^{\mathrm{d}}$ & $40,85^{\text {bdce }}$ \\
\hline Antep-2 & $3,76^{\mathrm{k}}$ & $12,01^{\mathrm{abc}}$ & $2,61^{\text {dcef }}$ & $2,34^{\mathrm{m}}$ & $0,21^{\mathrm{h}}$ & $15,70^{1}$ & $49,75^{\mathrm{ab}}$ \\
\hline Irak-1 & $8,47^{\mathrm{b}}$ & $11,22^{\mathrm{de}}$ & $2,59^{\mathrm{dcef}}$ & $2,15^{\mathrm{n}}$ & $0,22^{\text {fgh }}$ & $16,03^{\mathrm{h}}$ & $48,35^{\mathrm{ab}}$ \\
\hline Irak-2 & $4,59^{\mathrm{h} 1}$ & $10,01^{\mathrm{f}}$ & $2,69^{\mathrm{bcd}}$ & $9,93^{\mathrm{c}}$ & $0,42^{\mathrm{b}}$ & $24,48^{b}$ & $37,58^{\mathrm{de}}$ \\
\hline Irak-3 & $7,24^{\mathrm{c}}$ & $11,47^{\text {cde }}$ & $2,65^{\text {bcde }}$ & $5,30^{\mathrm{g}}$ & $0,34^{\text {cd }}$ & $20,79^{\mathrm{c}}$ & $40,82^{\text {bdce }}$ \\
\hline Kayseri-1 & $4,42^{1}$ & $12,37^{\mathrm{a}}$ & $2,89^{\mathrm{ab}}$ & $4,85^{\mathrm{h}}$ & $0,30^{\text {cde }}$ & $16,88^{\mathrm{g}}$ & $46,19^{\mathrm{e}}$ \\
\hline Maraş-1 & $4,05^{j}$ & $12,17^{\mathrm{ab}}$ & $2,75^{\mathrm{bc}}$ & $3,82^{1}$ & $0,28^{\text {def }}$ & $14,15^{\mathrm{m}}$ & $48,05^{\mathrm{abc}}$ \\
\hline Maraş-2 & $4,53^{\mathrm{hr}}$ & $11,43^{\text {cde }}$ & $2,33^{f}$ & $2,58^{1}$ & $0,22^{\text {fgh }}$ & $15,72^{1}$ & $50,92^{\mathrm{a}}$ \\
\hline Mardin-1 & $3,42^{1}$ & $12,21^{\mathrm{ab}}$ & $2,88^{\mathrm{ab}}$ & $6,56^{\mathrm{e}}$ & $0,36^{\mathrm{c}}$ & $16,99^{\mathrm{g}}$ & $44,17^{\text {abcd }}$ \\
\hline Urfa-1 & $4,73^{\text {gh }}$ & $11,62^{\text {bcd }}$ & $2,46^{\text {def }}$ & $10,45^{b}$ & $0,47^{\mathrm{ab}}$ & $14,75^{\mathrm{k}}$ & $43,61^{\text {abcd }}$ \\
\hline Urfa-2 & $6,03^{\mathrm{e}}$ & $11,56^{\text {cde }}$ & $2,41^{\mathrm{ef}}$ & $3,48^{j}$ & $0,25^{\text {efgh }}$ & $15,13^{j}$ & $48,47^{\mathrm{ab}}$ \\
\hline Urfa-3 & $4,91^{\mathrm{g}}$ & $11,54^{\text {cde }}$ & $2,49^{\text {cdef }}$ & $3,80^{1}$ & $0,27^{\mathrm{efg}}$ & $18,24^{\mathrm{f}}$ & $46,75^{\text {abcd }}$ \\
\hline Urfa-4 & $6,42^{d}$ & $11,81^{\text {abcd }}$ & $2,60^{\text {cdef }}$ & $3,41^{j}$ & $0,22^{\text {fgh }}$ & $15,12^{j}$ & $48,78^{\mathrm{ab}}$ \\
\hline Ortalama & 5,52 & 11,46 & 2,61 & 5,05 & 0,30 & 17,59 & 45,52 \\
\hline
\end{tabular}

Tablo 3 incelendiğinde genotiplere ait tohumların yağ oranlarının istatiksel düzeyde önemli olduğu görülmektedir $(\mathrm{P} \leq 0,01)$. Çemen tohumlarının yağ oranları \%3,01-5,34 arasında değiştiği, en yüksek yăg oranı Adana-1 genotipinde $(\% 5,34)$ tespit edildiği belirlenmiştir. $\mathrm{Bu}$ oran $1 \% 4,80$ ile Urfa-1 ve $\% 4,78$ Adana-2 genotipi takip etmiştir. En düşük yağ oran1 Afganistan-2 genotipinde $(\% 3,01)$ saptanmıştır. Üç lokasyondan alınan çemen tohumlarında yapılan bir çalışmada yă̆ oranı \%7,1-8,82 arasında değişim göstermiştir [7]. Suuidi Arabistan koşullarında yetiştirilen çemen tohumlarının yağ oranları $\% 4,51$ olarak saptamıștır [13]. Kahramanmaraş koşullarında çeşit ve ekim zamanının etkisinin araştırıldığı çalışmada yă̆ oranlarının \%5,4-6,6 arasında değiştiği bildirilmiştir [14]. Ayrıca Kayseri ilinden temin edilen çemen otunun \%0,9-1,85 arasında, tohumunun ise $\% 5$ oranında yağ içerdiği bildirilmiştir [15]. Bulgularımız Gökçe [14] ve Kırılan ve ark. [7] tarafindan bildirilen değerlerden düşük çıkarken, AlJasass ve Al-Jasser [13]; Özçelik ve Şahin [15] tarafından bildirilen değerler ile uyumlu çıkmıştır.

Gaz kromatografi sonuçlarına göre; çemen tohumları toplam 17 yağ asit bileşenleri içermektedir. Fakat bu yağ asidi bileşenlerinin yaklaşık olarak \%97'si miktar bakımından 5 yağ asidinde toplanmıştır. Bu nedenle linoleik asit, gama-linolenik asit, oleik asit, palmitik asit ve stearik asit değerleri incelenmiştir. Araştırmada tüm yağ asitleri istatistiki açıdan önemli olduğu $(\mathrm{P} \leq 0,01)$ saptanmıştır. Araştırma bulguları incelendiğinde linoleik asit \%36,92-43,82, gama- linolenik asit \%23,39-29,74, oleik asit \%12,79-19,27, palmitik asit \%9,77-13,68 ve stearik asit \%3,5-4,8 arasında değiştiği tespit edilmiştir. Sonuçlar incelendiğinde en yüksek değerler linoleik asit $(\% 43,82)$ Irak-1 genotipinde, gama-linolenik asit $(\% 29,74)$ Urfa-3 genotipinde, oleik asit $(\% 19,27)$ Maraş-2 genotipinde, palmitik asit $(\% 13,68)$ Urfa-1 genotipinde ve stearik asit \%4,8 ile Urfa-1 genotipinde saptanmıştır (Tablo 3).

Araştırmada çemen tohumlarının \%36,92-43,82 ve çemen vejetatif aksamının \%14,15-29,83 linoleik asit içerdiği tespit edilmiştir. Araştırma sonucunda çemen tohumlarının vejetatif aksama göre yüksek miktarda linoleik asit içerdiği gözlemlenmektedir. Gökçe [14] tarafindan yapılan çalışmada çemen tohumlarının $\% 41,6$, Akbari ve ark. [16] tarafindan yapılan çalışmada tohumların \%54,13 oranında linoleik asit içerdiği belirtilmiştir. Çalışmada çemen tohumları linoleik asitten sonra en fazla gama-linolenik asit (\%23,39-29,74) içermektedir ve bulgularımız Kıralan ve ark. [7] tarafindan bildirilen değerlerden yüksek çıkmıştır. Çemen vejetatif aksamı \%0,20-0,51 tohumları ise \%13,45-19,27 arasında oleik asit içerdiği saptanmıştır. Çemen tohumlarında tespit edilen oleik asit oranı Gökçe [14] ve Kıralan ve ark. [7] tarafindan bildirilen bulgular ile uyumludur.

Farklı çemen genotiplerinin kullanıldı ̆̆ı çalışmada palmitik asit oranları çemen vejetatif aksamında $\% 10,01-12,37$ arasında, tohumlarında ise \%9,7713,68 olarak tespit edilmiștir. Stearik asit oranları 
incelendiğinde çemen vejetatif aksamında \%2,333,03 arasında değiştiği bu değerin tohumlarında \%3,5-4,1 oranları arasında değiştiği saptanmıştır. Araştırma sonuçlarına göre çemen tohumlarının ve vejetatif aksamlarının stearik asit ve palmitik asit oranlarının birbirine yakın olduğu görülmektedir.
Fakat çemen vejetatif aksamının araşidik asit, bütirik asit ve elaidik asit bakımından tohumlarına göre daha zengin olduğu söylenebilir. Araştırmada çemen vejetatif aksamı \%37,34-50,92 araşidik asit içerirken, Akbari ve ark. [16] tarafindan tohumlarda yapılan çalışmada bu oranın \%0,4 olduğu bildirilmiştir.

Tablo 3. Çalıșmada kullanılan çemen genotiplerinin tohumlarında belirlenen yağ oranı ve yağ asidi bileșenleri (\%)

\begin{tabular}{|c|c|c|c|c|c|c|}
\hline Genotipler & Yağ oranı & Linoleik asit & $\gamma$-Linolenik asit & Oleik asit & Palmitik asit & Stearik asit \\
\hline & $* *$ & $* *$ & $* *$ & $* *$ & $* *$ & $* *$ \\
\hline Adana-1 & $5,34^{\mathrm{a}}$ & $41,49^{d}$ & $28,93^{\mathrm{bc}}$ & $13,45^{\mathrm{j}}$ & $10,19^{\mathrm{ij}}$ & $3,8^{g}$ \\
\hline Adana-2 & $4,78^{b}$ & $42,35^{\mathrm{c}}$ & $27,22^{\mathrm{d}}$ & $14,35^{\mathrm{gh}}$ & $10,55^{\text {fgh }}$ & $3,6^{j}$ \\
\hline Adana-3 & $4,43^{\mathrm{de}}$ & $39,76^{\mathrm{h}}$ & $28,21^{\mathrm{c}}$ & $14,77^{\mathrm{g}}$ & $10,72^{\text {def }}$ & $4,0^{d}$ \\
\hline Afganistan-1 & $3,40^{j}$ & $42,89^{b}$ & $25,34^{f}$ & $15,79^{f}$ & $10,32^{\text {ih }}$ & $3,6^{\mathrm{j}}$ \\
\hline Afganistan-2 & $3,01^{1}$ & $40,16^{\mathrm{g}}$ & $29,68^{a b}$ & $14,05^{\mathrm{h} 1}$ & $10,77^{\text {ef }}$ & $3,7^{1}$ \\
\hline Antep-1 & $4,07^{\mathrm{h}}$ & $39,63^{h}$ & $24,43^{\mathrm{g}}$ & $18,59^{b}$ & $10,84^{\text {cde }}$ & $4,0^{\mathrm{cd}}$ \\
\hline Antep-2 & $4,17^{\text {gh }}$ & $40,83^{f}$ & $28,98^{\mathrm{abc}}$ & $14,30^{\mathrm{gh}}$ & $10,32^{\text {hh }}$ & $3,6^{\mathrm{j}}$ \\
\hline Irak-1 & $3,22^{j}$ & $43,82^{a}$ & $23,96^{\text {gh }}$ & $16,34^{\mathrm{e}}$ & $10,66^{\text {defg }}$ & $3,4^{\mathrm{m}}$ \\
\hline Irak-2 & $4,26^{\mathrm{fg}}$ & $41,65^{d}$ & $27,32^{d}$ & $14,75^{\mathrm{g}}$ & $10,54^{\text {fgh }}$ & $3,5^{1}$ \\
\hline Irak-3 & $4,25^{\mathrm{fg}}$ & $40,83^{f}$ & $28,40^{\mathrm{c}}$ & $14,36^{\mathrm{gh}}$ & $9,77^{\mathrm{k}}$ & $3,6^{\mathrm{k}}$ \\
\hline Kayseri-1 & $4,45^{\text {cde }}$ & $37,75^{k}$ & $25,59^{f}$ & $17,20^{\mathrm{cd}}$ & $10,61^{\text {efg }}$ & $4,1^{b}$ \\
\hline Maraş-1 & $4,40^{\mathrm{de}}$ & $38,91^{\mathrm{j}}$ & $23,39^{\mathrm{h}}$ & $18,14^{b}$ & $11,21^{\mathrm{b}}$ & $3,8^{g}$ \\
\hline Maraş-2 & $4,57^{\mathrm{c}}$ & $39,38^{1}$ & $23,77^{\text {gh }}$ & $19,27^{\mathrm{a}}$ & $11,04^{b c}$ & $3,8^{\mathrm{g}}$ \\
\hline Mardin-1 & $4,32^{\text {ef }}$ & $41,17^{\mathrm{e}}$ & $26,87^{\mathrm{de}}$ & $16,76^{\text {de }}$ & $10,18^{1 j}$ & $3,7^{\mathrm{h}}$ \\
\hline Urfa-1 & $4,80^{b}$ & $36,92^{1}$ & $23,96^{\text {gh }}$ & $17,41^{\mathrm{c}}$ & $13,68^{\mathrm{a}}$ & $4,8^{\mathrm{a}}$ \\
\hline Urfa-2 & $4,13^{\text {ght }}$ & $41,40^{\mathrm{de}}$ & $26,37^{\mathrm{e}}$ & $15,60^{\mathrm{f}}$ & $10,46^{\mathrm{gh}}$ & $4,0^{\mathrm{c}}$ \\
\hline Urfa-3 & $4,02^{1}$ & $40,12^{g}$ & $29,74^{\mathrm{a}}$ & $12,79^{\mathrm{k}}$ & $10,03^{j}$ & $3,8^{f}$ \\
\hline Urfa-4 & $4,52^{\mathrm{cd}}$ & $40,30^{\mathrm{g}}$ & $28,89^{b c}$ & $13,59^{1 j}$ & $10,89^{\mathrm{cd}}$ & $3,9^{\mathrm{e}}$ \\
\hline Ortalama & 4,23 & 40,51 & 26,73 & 15,64 & 10,71 & 3,8 \\
\hline
\end{tabular}

**: $\mathrm{P} \leq 0,01$ düzeyinde önemli

\section{SONUÇ}

Farkl1 çemen genotiplerinin vejetatif aksam ve tohumlarının yağ asit bileşenlerinin incelendiği çalışmada, vejetatif aksamda toplamda 31 ve tohumlarında toplam 17 yağ asidi bileşeni saptanmıştır. Bu bağlamda çemen bitkisinin vejetatif aksamı tohumlarına göre yağ asit içeriği bakımından zengin olduğu söylenebilir. Ayrıca çalışmada, çemen bitkisinin vejetatif aksamının araşidik asit, tohumlarının ise linoleik, gama-linolenik ve oleik asit içeriği bakımından yüksek olduğu belirlenmiştir. Yapılan araştırmada sonucunda çemen bitkisinin hem vejetatif aksamının hem de tohumunun yağ asit bileşenleri bakımından zengin bir bitki olduğu sonucuna varılmıştır.

\section{Teșekkür}

Bu çalışmanın bir kısmı Fatma AKBAY'ın Yüksek Lisans tezinden hazırlanmıștır.

\section{KAYNAKLAR}

[1] Acharya SN, Thomas JE, Basu SK. Fenugreek: an "old world" crop for the "new world". Biodiversity. 2006; 7:27-30.

[2] Gupta K, Thakral KK, Arora SK, Chowdhary ML. Structural carbohydrate and mineral contents of fenugreek seeds Indian Cocoa. Arecanut and Spices Journal. 1996; 20(4):1201124.

[3] Żuk-Gołaszewska K, Wierzbowska J. Fenugreek: productivity, nutritional value and uses. Journal of Elementology. 2017; 22(3):1067-1080

[4] Baldemir A, İlgün S. Geçmişte ve günümüzde çemen otunun kullanım alanları: Trıgonella foenum-graecum L. Lokman Hekim Journal. 2015; 5(1):1-4.

[5] Mir Z, Mir PS, Acharya SN, Zaman MS, Taylor WG, Mears GJ, Goonewardene LA. Comparison of alfalfa and fenugreek silages supplemented with barley grain on performance of growing steers. Canadian Journal of Animal Science. 1998; 78:343-349.

[6] Meghwal M, Goswami TK. A review on the functional properties, nutritional content, medicinal utilization and potential application of fenugreek. Journal Food Processing \& Technology. 2012; 3:1-10.

[7] Kıralan M, Yorulmaz A, Çalıkoğlu E, Bayrak A. Çemen otu (Trigonella foenum-graecum L.) tohumunun yağ asitleri ve sterol bileşimi. Derim. 2017; 34(2):138-141

[8] Eseceli H, Değirmencioğlu A, Kahraman R. Omega yağ asitlerinin insan sağlığı yönünden önemi. Türkiye 9. G1da Kongresi. Bolu; 2006.

[9] Gürcan Ü. Yağ Rafinasyonunda Oluşan Trans Yağ asitleri. Y. L. T. S. Ü. Fen Bilimleri Enstitüsü. Konya; 2001.

[10] Das U. Essential fatty acids enhance free radical generation and lipid peroxidation toinduce apoptosis of tumor cells, Clinical Lipidology. 2011; 6(4):463-489.

[11] AOAC. Official method of analysis. Association of official analytical chemists 15th.edition, 1990. p.66-88. 
[12] SAS. SAS Institute Inc., SAS/STAT User's Guide, Version 8, SAS INSTITUTE Inc., Cary, NC. 1999.

[13] Al-Jasass FM, Al-Jasser MS. Chemical composition and fatty acid content of some spices and herbs under Saudi Arabia conditions. The Scientific World Journal. 2012; 1:1-5.

[14] Gökçe Z. Kahramanmaraş koşullarında ekim zamanlarının çemen'de (Trigonella foenumgraecum L.) verim ve kalite üzerine etkisi. Kahramanmaraş Sütçü İmam Üniversitesi, Fen Bilimleri Enstitüsü, Tarla Bitkileri Anabilim Dalı, Yüksek Lisans; 2015.

[15] Özçelik ŞN, Şahin A. Çemen (Trigonella Foenum- Graecum L.) otunun ve tohumunun besin madde içerikleri ve in vitro sindirilebilirliğinin belirlenmesi. Hayvan Bilimi ve Ürünleri Dergisi. 2018; 1(1): 25-35.

[16] Akbari S, Abdurahman NH, Yunus RM, Alara OR, Abayomi OO. Extraction, characterization and antioxidant activity of fenugreek (Trigonella-foenum graecum) seed oil. Materials Science for Energy Technologies. 2019; 2:349-355. 